\title{
AVALIAÇÃO DE IMPLANTAÇÃO DA COLETA SELETIVA EM MUNICÍPIOS DE PEQUENO PORTE - ESTUDO DE CASO DA CIDADE DE IRATI (PR)
}

\author{
Waldir Nagel Schirmer ${ }^{* 1}$, Felipe Ramon Less ${ }^{2}$, Boanerges Carneiro Júnior ${ }^{3}$, Joenilson Daniel Agassi ${ }^{4}$, Rozenilda Romaniw \\ Barbara $^{5}$, Rafaelo Balbinot ${ }^{6}$ \\ 1 - Departamento de Eng. Ambiental da Universidade Estadual do Centro-oeste, Irati-PR, Brasil. \\ 2,3,4 - Engenheiro Ambiental pela Universidade Estadual do Centro-oest, Irati-PR, Brasil. \\ 5 - Prefeitura Municipal de Irati-PR, Brasil. \\ 6 - Departamento de Engenharia Florestal da Universidade Federal de Santa Maria, Frederico Westphalen-RS, Brasil.
}

*E-mail: wanasch@yahoo.com.br

Recebido em 12 de abril de 2009

Aceito em 30 de junho de 2009

\begin{abstract}
RESUMO
Em geral, o gerenciamento do lixo urbano vem sendo realizado de forma precária pelas administrações municipais brasileiras. Porém, segundo o IBGE, vem se verificando uma forte tendência de melhora na situação de destinação final do lixo coletado no país nos últimos anos. A geração de resíduos depende de vários fatores tais como nível cultural, hábito de consumo, renda, clima, sexo e idade da população e a sua redução está atrelada a um programa de gerenciamento com base em três aspectos: redução na fonte, reutilização e reciclagem. O presente trabalho tem como objetivo principal a implantação de um programa de coleta seletiva em todo o quadro urbano da cidade de Irati (PR) através da Associação de Catadores do Município. A proposta de implantação da coleta seletiva foi dividida em duas etapas: logística e educação ambiental, ambas já sendo cumpridas. Nos doze primeiros meses de programa, os resultados mostraram um aumento considerável no volume de material coletado desde o início do programa, atingindo $11,5 \%$ do material gerado na cidade proporcionando emprego fixo e renda para 24 catadores de papéis que até então trabalhavam informalmente nas ruas da cidade. Com base no total arrecadado ao longo desses 12 meses iniciais, conclui-se que a economia pode chegar a 420 mil reais, caso todo o material arrecadado seja utilizado como matéria prima na fabricação de novos materiais.
\end{abstract}

Palavras-chave: Coleta seletiva; Irati (PR); Lixo; Reciclagem; Resíduos sólidos urbanos.

\section{INTRODUÇÃO:}

Os resíduos sólidos gerados atualmente têm como característica a heterogeneidade, a qual acaba lhe conferindo características específicas e propriedades físicas desiguais. Da associação dessas características decorre a grande dificuldade encontrada em seu manuseio pois, em geral, levam muito mais tempo para serem degradados do que os de origem natural. As formas mais tradicionais de disposição dos resíduos sólidos urbanos são: aterro sanitário, lixões (vazadouros a céu aberto), compostagem e incineração.

Na Conferência Eco-Rio 92 [1], foi apresentada uma forma de gestão sustentável dos resíduos sólidos baseada numa abordagem que tem como referência o princípio dos $3 \mathrm{R}$. Em primeiro lugar, redução do uso de matérias-primas e energia e do desperdício nas fontes geradoras. Antes, ainda, é necessário verificar se não será possível evitar a produção daquele produto ("futuro resíduo"), por exemplo, utilizando produtos fabricados de forma diferente e/ou prolongando o tempo de vida útil do produto. Em segundo lugar, reutilização direta dos produtos, é necessário verificar se não é possível encontrar uma nova serventia para esse produto, em que grande parte das suas propriedades ainda possam ser rentabilizadas. Por fim, a reciclagem de materiais, quando não for possível aproveitar grande parte do valor do produto, pode-se tentar essa terceira alternativa, ou seja, aproveitar a matéria prima que o constitui, em alguns casos para fabricar produtos idênticos. Nesse mesmo contexto, Brown [2] citado por Rolim [3], introduziu mais um princípio, o de recuperar, incluindo mais um $\mathrm{R}$ na gestão dos resíduos, que significa reciclar um material extraído de resíduos misturados ou de resíduos de outros processos.

Segundo Calderoni [4], a reciclagem proporciona economia de matérias primas e, conseqüentemente, a diminuição de áreas degradadas pela sua extração. A reciclagem de uma tonelada de alumínio, por exemplo, economiza 5 toneladas de bauxita, e o mesmo ocorre com a reciclagem do aço, que gera uma economia de $1.140 \mathrm{~kg}$ de minério de ferro, $154 \mathrm{~kg}$ de carvão e $18 \mathrm{~kg}$ de cal; para o papel, uma tonelada de aparas pode substituir de 2 a $4 \mathrm{~m}^{3}$ de madeira; para o vidro, a economia de matéria prima é de 202,5 kg de areia, $66 \mathrm{~kg}$ de barrilha e 59,9 kg de calcário e para o plástico, economiza-se em média uma tonelada de petróleo em energia considerando todo o processo desde a 
exploração da matéria-prima até a formação do produto final [5]. Ainda neste sentido, a reciclagem propicia o surgimento de novos negócios e de geração de renda, pois implica na criação de empregos, diretos e indiretos. Propicia ainda o aumento da vida útil dos aterros sanitários e a promoção da consciência ambiental na população.

A reciclagem de qualquer material envolve um processo de logística que compreende basicamente as seguintes etapas: coleta, seleção, revalorização e transformação. A Coleta Seletiva é a primeira e mais importante etapa da reciclagem, tendo como objetivo recolher os materiais recicláveis previamente separados na fonte geradora. Caso não haja essa separação previa, muitos materiais recicláveis acabam se misturando com outros resíduos podendo comprometer todo o processo.

Segundo CEMPRE [6], a reciclagem no Brasil movimenta cerca de sete bilhões de reais por ano. Quase a totalidade dos municípios brasileiros possui sistema de reciclagem dos resíduos domiciliares; porém, a coleta seletiva está presente em apenas 4,3\% destes municípios. Uma forte tendência é a terceirização da coleta seletiva, através de parcerias com diversas entidades.

De maneira geral, a coleta seletiva se fundamenta no tripé Tecnologia (que neste trabalho é tratado com o termo logística), envolvendo as etapas de coleta, separação e envio às recicladoras; Educação Ambiental, onde é feita a transmissão de informação para motivação da população; e Mercado, absorção do material reciclado [7]. Em termos de logística, é necessária a disponibilidade de mão-de-obra e veículos necessários para efetuar a coleta, uma central de triagem, ou seja, uma estrutura (de preferência um barracão fechado) com boxes para a armazenagem dos materiais separados, além de prensas para o enfardamento do material, esteiras de catação e local para estocagem [7]. Educação Ambiental é o instrumento capaz de capacitar os indivíduos, por meio de conscientização, a entenderem as questões ambientais, sensibilizando-os para o reconhecimento do seu papel atuante na sociedade e nas mudanças de atitude. E conscientização só ocorre através da efetiva transmissão de informação [8].

O presente trabalho teve como objetivo principal a implantação de um programa de coleta seletiva em todo o quadro urbano da cidade de Irati (PR) através da Associação de Catadores do Município. Visou ainda ao estabelecimento das principais diretrizes do programa, tanto na parte de logística (estruturação geral) quanto de sensibilização do sistema; à melhoria da qualidade de vida dos catadores com o aumento de suas rendas e melhores condições de trabalho; à melhoria nas condições de saneamento da cidade; à educação ambiental, criando novos hábitos e sensibilizando a população iratiense sobre questões ambientais (diminuição dos resíduos gerados, importância e benefícios de um sistema de coleta, etc.); ao aumento do tempo de vida útil do aterro da cidade e região e, por fim; à conservação dos recursos naturais pela reutilização dos materiais descartados.

\section{Materiais e métodos}

A proposta de implantação da coleta seletiva foi dividida em duas etapas: Logística e Educação ambiental, ambas já sendo cumpridas e com resultados parciais.

\subsection{Logistica}

A cidade de Irati (PR) tem uma população urbana de aproximadamente 55.000 habitantes, dividida em vinte bairros, cerca de 13.000 residências na área urbana e uma extensão (total) de ruas de $310 \mathrm{Km}$. Como o município não possui equipamento para pesagem, a quantidade de lixo coletada diariamente foi estimada, considerando-se os seguintes fatores: número de viagens realizadas pelos caminhões de coleta, sua capacidade volumétrica, peso específico do lixo, tipo de caminhão empregado na coleta (compactador), e sua capacidade de carga volumétrica.

Como não foi feita a caracterização do lixo da cidade de Irati, a quantidade de material reciclável foi estimada seguindo trabalhos de caracterização em cidades de pequeno porte de acordo com a literatura, como o sugerido por Magera, Robles e Fiocco [9] através do software VERDES

O programa de coleta seletiva contempla, em linhas gerais, o seguinte procedimento, já implementado no município:

- a coleta é realizada uma vez por semana em cada bairro (no Centro é feito duas vezes). Os vinte bairros foram divididos de acordo com a proximidade entre si, pela população residente e pela extensão de ruas, objetivando manter uma quantidade média de casas a serem atendidas e extensão percorrida, em todos os dias da semana, além de serem separados em um sistema em que a coleta seletiva é feita no sentido leste-oeste na cidade.

- o sistema de separação adotado foi o sistema "seco e úmido", os quais correspondem a recicláveis e não recicláveis, respectivamente.

- os vinte e quatro catadores são divididos em dois grupos, onde um grupo fica responsável pela coleta (10 carrinheiros e um caminhão com 3 catadores fazendo o serviço de campo) e outro pela triagem (11 separadores). O seu trabalho se dá em dois turnos de segunda a sexta-feira e no sábado apenas na parte da manhã.

- a extensão média percorrida por cada carrinheiro foi calculada em 3,1 Km, a partir da Equação (1):

Extensãocarrinheiø $=\frac{\text { Extensã } ₫ \text { las ruas }}{\left(\text { dias da semana } \times \mathrm{n}^{0} \text { deturno } \times \mathrm{n}^{\circ} \text { de carrinheiøs }\right)}$

Os carrinheiros são levados a pontos estratégicos pelo caminhão (ou a locais onde os carrinhos pernoitaram) onde ficam próximos à sua área de coleta. A área de coleta de cada carrinheiro contém ruas que devem ser feitas com locais de referência para facilitar sua localização. Os carrinheiros recolhem em sacolas o material reciclável, que depois de preenchidas são deixadas na rua (Figura 1.a), e continuam fazendo as rotas determinadas até o final onde estará o caminhão de apoio, que recolhe a coleta de posse dos carrinheiros e os materiais deixados no caminho (Figura 1.b) e os levam para a triagem. 


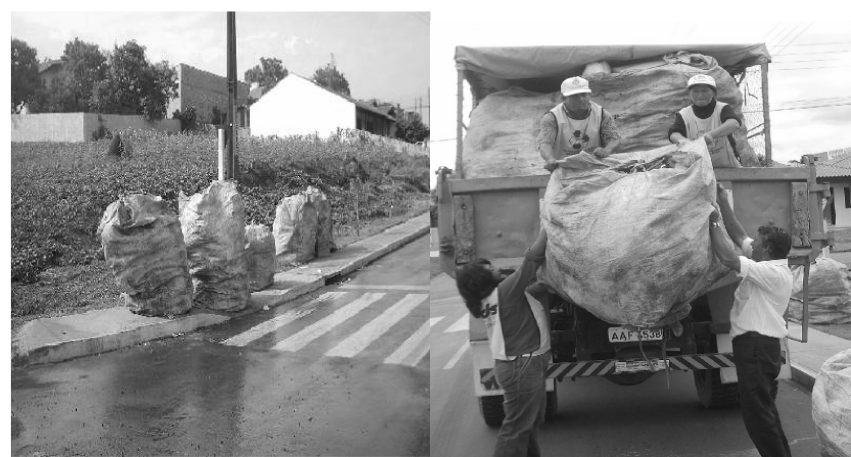

Figura 1 - a) Sacos preenchidos nas ruas b) Caminhão carregando os sacos.

- já no barracão, é iniciada a triagem desde o momento em que o material é descarregado. Neste caso, os resíduos são retirados das sacolas e os rejeitos são separados dos materiais que possam deteriorar ou perder qualidade se permanecer misturados (tais como papel, papelão) sendo depois são levados para as mesas de triagem, etapa esta realizada por quatro separadores. Nas mesas de triagem, ocorre a separação dos materiais de acordo com a sua composição e são depositados sacos localizados ao redor das mesas (em cada mesa ficam dois ou três separadores). Depois do preenchimento dos sacos, os materiais são recolhidos, prensados (Figura 2.a), pesados e encaminhados para o estoque (Figura 2.b). Quando é completado peso suficiente, o material é vendido a empresas beneficiadoras e intermediadoras, aquelas que irão comercializar para as indústrias.
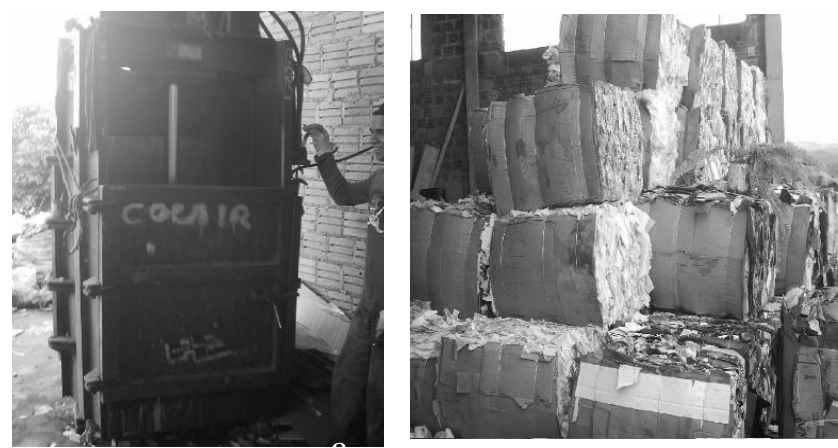

Figura 2 - a) Prensa para enfardamento e b) área de estocagem dos materiais.

A realização da etapa de logística compreendeu a aquisição de equipamentos que dessem suporte ao projeto, como barracão de triagem de $400 \mathrm{~m}^{2}$, sede com escritório, vestiário e área para reuniões e estocagem do material prensado $\left(300 \mathrm{~m}^{2}\right), 10$ carrinhos de coleta, 3 mesas de triagem, prensa, balança, novos equipamentos de proteção individual (EPI) para os associados, sacos de coleta, bem como a readequação da estrutura já existente, como a formação de pessoal destinado à função, realocação de caminhão (cedido pela Prefeitura Municipal de Irati), e verba mensal referente ao salário dos catadores para os três primeiros meses, dentre outros itens necessários ao trabalho.

\subsection{Educação Ambiental}

A etapa de divulgação e mobilização da população iniciou-se duas semanas antes do início da coleta propriamente dita; foram confeccionados "folders" explicativos sobre o sistema de coleta, contendo a frequiência e locais de coleta para serem distribuídos à comunidade (Figura 3). Concomitantemente a este trabalho, houve mobilização de alunos e professores universitários do curso de Engenharia Ambiental da Universidade Estadual do Centro Oeste (UNICENTRO) para o trabalho de educação ambiental, em que foram realizadas visitas aos estabelecimentos comerciais e residências na área central da cidade e de um bairro. A abordagem nas residências foi feita com forte apelo à promoção da preservação e conservação do ambiente, valorização da cultura, inclusão social, qualidade de vida, ampliação da geração de renda para vários desempregados, além de esclarecimentos como freqüência e horário da coleta e modo de separação dos resíduos.

As escolas municipais, estaduais e particulares foram mobilizadas com palestras que tinham como tema a finalidade e a importância da separação do lixo e explicação de como funcionaria a coleta seletiva, além de distribuição do "folder" a este público. Também fez-se uso da imprensa (rádio e jornal locais), informando a população do projeto.

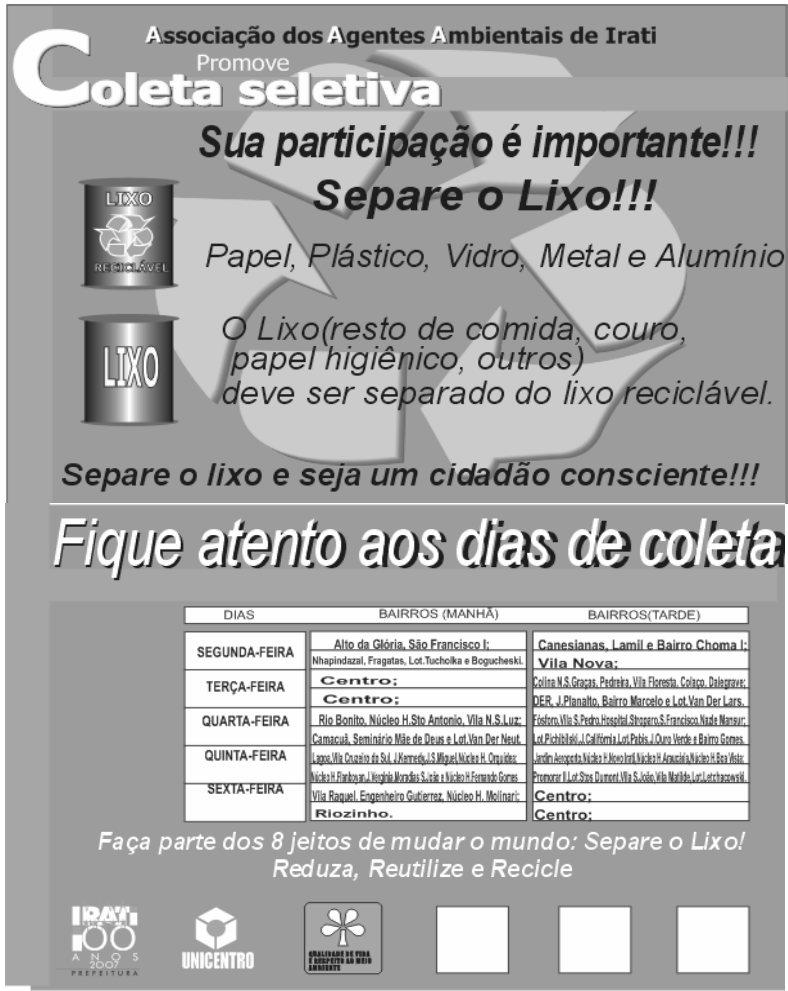

Figura 3 - "Folder" utilizado na campanha de Educação Ambiental (frente e verso).

\section{Resultados e discussões}

Diariamente, são coletados e encaminhados ao aterro sanitário 17 toneladas de resíduos, compreendendo um valor per capita de 420 gramas.dia ${ }^{-1}$. Desse montante, foi 
estimado que pelo menos 10,5 ton (62\%) são resíduos recicláveis. Foi visitada, em uma semana, cerca de $25 \%$ da cidade, nos quais 500 estabelecimentos comerciais e 2000 residências, por cerca de 40 alunos da Engenharia Ambiental, onde houve uma boa aceitação da população; além disso, foram visitadas 20 escolas municipais, estaduais e particulares, abrangendo um total de mais de 5000 alunos.

Nos três primeiros meses de programa, etapa de formação de estoque, a cooperativa recebeu o apoio da prefeitura municipal, que repassava cerca de $\mathrm{R} \$ 300,00$ por mês por integrante da cooperativa, afim de que pudessem fechar o ciclo de coleta e comercialização, garantindo assim a sobrevivência da produção. Nesse período, a cooperativa contou ainda com o apoio da prefeitura no pagamento das contas de água e luz, alimentação, motorista e óleo diesel (o que ocorre ainda hoje). Nesses três meses, estima-se que foram coletadas cerca de 150 ton de material reciclável (média de 1,8 ton.dia ${ }^{-1}$ ). Destas 150 ton, 50 ton (cuja composição é mostrada na Tabela 1) foram comercializadas.

Tabela 1 - Composição e peso do material reciclável vendido nos 3 meses iniciais.

\begin{tabular}{ccc}
\hline Produtos & Total $(\mathbf{k g})$ & Contribuição (\%) \\
\hline Papelão & 14.160 & 28,1 \\
Papel Branco & 2.760 & 5,5 \\
Papel Misto & 5.603 & 11 \\
PEAD & 2.977 & 5,9 \\
PET & 5.612 & 11,1 \\
PP & 4.907 & 9,7 \\
PS & 218 & 0,4 \\
Alumínio & 966 & 1,9 \\
Tetra Pack & 1.127 & 2,2 \\
Ferro & 5.093 & 10,1 \\
Vidro & 6.994 & 13,9 \\
Total & $\mathbf{5 0 . 4 1 7}$ & $\mathbf{1 0 0 , 0}$
\end{tabular}

(PP): polipropileno (PET): teraftalato de polietileno (PEAD): polietileno de alta densidade (PS): Poliestireno

Pode ser observado, pela quantidade de papel e papelão arrecadado nos três primeiros meses do projeto, o excelente reflexo da primeira etapa de conscientização, onde foram visitados praticamente todos os estabelecimentos comerciais da cidade.

Considerando-se que a cidade produz 10,5 ton por dia de material reciclável (estimativa), o que daria, nesses 3 primeiros meses, 945 ton de material reciclável, pode-se concluir que o programa de coleta seletiva atingiu cerca de $16 \%$ do material total reciclável.

Numa segunda etapa do projeto, que compreendeu os 9 meses seguintes, a cooperativa passou a ser autosuficiente no que se referia à alimentação, proporcionando ainda um rateio resultante da comercialização da produção dos associados. O programa incluiu ainda dois bairros da zona rural de Irati no programa, em que o material reciclável passou a ser coletado no sábado. Também foram oferecidas palestras sobre o tema a todos os professores da rede de ensino, curso de educação ambiental para crianças de $1^{\mathrm{a}}$ a $4^{\mathrm{a}}$ séries e oficinas para reaproveitamento de garrafas PET para a comunidade.

Nesta etapa, foram coletadas mais de 285 ton de material reciclável cuja composição é apresentada na Tabela 2. Nesses 9 meses, levando-se em conta uma estimativa de material reciclável de 2835 ton (10,5 ton.dia $\left.{ }^{-1}\right)$, conclui-se que o programa de coleta seletiva atingiu cerca de $10 \%$ do material reciclável, o qual deixou de ser destinado ao aterro sanitário, ou seja, pôde ser reutilizado na fabricação de novos produtos (de metal, plástico, vidro e papel).

Tabela 2 - Composição e peso médio do material reciclável coletado nos últimos 9 meses.

\begin{tabular}{ccc}
\hline Produtos & Total $\mathbf{( k g )}$ & Contribuição $\mathbf{( \% )}$ \\
\hline Papelão & 47.862 & 10,5 \\
Papel Branco & 19.611 & 4,3 \\
Papel Misto & 34.461 & 7,6 \\
PEAD & 26.037 & 5,7 \\
PET & 45.018 & 9,9 \\
PP & 14.742 & 3,2 \\
PS & 1.845 & 0,4 \\
Alumínio & 8.478 & 1,9 \\
Tetra Pack & 7.371 & 1,6 \\
Ferro & 13.743 & 3,0 \\
Vidro & 66.366 & 14,6 \\
Total & $\mathbf{2 8 5 . 5 1 6}$ & $\mathbf{1 0 0}$ \\
\hline
\end{tabular}

(PP): polipropileno (PS): Poliestireno (PEAD): polietileno de alta densidade (PET): teraftalato de polietileno

O percentual encontrado na segunda etapa $(10 \%)$ ficou abaixo daquele verificado nos 3 meses iniciais (16\%). Entretanto, apesar da quantidade média de material reciclável arrecadado na segunda etapa ter sido menor que nos três meses iniciais (proporcionalmente ao período), verificou-se uma melhora significativa na composição do material arrecadado, o que representou uma menor taxa de rejeitos acumulados nessa etapa. O material coletado nos três primeiros meses, por ser uma etapa de adaptação ao programa (principalmente por parte da população), ainda continha bastantes resíduos não recicláveis (putrescíveis), o que acabava contaminando o restante do material (reciclável).

Fazendo a média ponderada das duas etapas chegou-se ao resultado de $11,5 \%$ de material arrecadado. Apesar deste índice de material reciclável arrecadado ainda ser relativamente baixo, estima-se que a média de adesão da população ultrapassa $50 \%$ das casas. Esses dados devem nortear as novas campanhas de Educação Ambiental, que devem estar voltadas para a separação correta dos materiais recicláveis, pois esses dados indicam que muito material reciclável ainda está sendo destinado ao aterro sanitário, inclusive pela população que aderiu à coleta.

$\mathrm{Na}$ análise dos $50 \%$ da população que não foram atingidos pela campanha, segundo Hyman e Sheatsley [10] (citado por Ferreira [11]), cientistas americanos que estudaram as campanhas de informação e persuasão, existem vários fatores a serem considerados. Estes podem estar ligados à existência de um grupo de "ignorantes crônicos" 
ou "desinformados", que os torna difícil de serem atingidos independentemente do nível ou da natureza das informações. Tendo em vista esses fatores, os cientistas sociais concluíram que a eficiência dessas campanhas para alterar atitudes ou comportamentos é limitada.

É necessário, tendo em vista esta limitação nas campanhas, que se criem mecanismos por parte do poder público através da elaboração de leis mais específicas que incentivem a população à adesão e continuidade de quem já participa, mecanismos estes que podem estar relacionados a aspectos econômicos, tais como uso de tarifas do lixo, estabelecendo uma cobrança diferenciada. Apesar dos estabelecimentos de ensino formal já demonstrarem interesse crescente pelo tema e a educação ambiental já ser trabalhada de forma transdisciplinar, é necessário que a educação ambiental seja desenvolvida num processo dentro e fora das salas de aula, envolvendo além das crianças, pais e professores, já que estes são os transmissores de informação [12].

A renda obtida pelos 24 associados com a venda do material reciclável arrecadado alcançou em média, R \$ 300 mensais. Para a Prefeitura Municipal de Irati, nesse primeiro ano de implantação do sistema, houve uma economia de R\$ 13.437 que seriam destinados à disposição desses resíduos, tendo em vista que o custo (médio) de coleta e destinação final é de R\$ 40 por tonelada. Além disso, houve o aumento da vida útil do aterro em 66 dias, já que o volume encaminhado diariamente ao aterro foi reduzido em $18 \%$.

Com relação às economias e ganhos de ordem ambiental, destaca-se a economia no uso da energia elétrica. Nesse caso, a Tabela 3 relaciona o custo de produção da quantidade de material arrecadado caso os mesmos fossem produzidos a partir de sua matéria prima.

Tabela 3 - Valor gasto na produção de novos materiais a partir de sua matéria prima.

\begin{tabular}{cccc}
\hline Material & $\begin{array}{c}\text { Quantidade } \\
\text { (ton) }\end{array}$ & $\begin{array}{c}\text { Energia necess. } \\
\left.\text { (MWh.ton }^{-1}\right)^{(\mathbf{1})}\end{array}$ & $\begin{array}{c}\text { Total } \\
(\mathbf{R} \mathbf{\$})^{(\mathbf{2})}\end{array}$ \\
\hline $\begin{array}{c}\text { Metais } \\
\text { não } \\
\text { ferrosos }\end{array}$ & 9,4 & 17,60 & $57.904,00$ \\
Papel e & 133,0 & 4,98 & $231.819,00$ \\
papelão & & & \\
Plástico & 101,4 & 6,74 & $239.202,00$ \\
Metais & 18,8 & 13,33 & $87.711,00$ \\
ferrosos & & & \\
Vidro & 73,4 & 4,83 & $124.083,00$ \\
Total & 335,9 & - & $740.719,00$
\end{tabular}

(1) Energia gasta para fabricação de 1 tonelada do produto final a partir da matéria prima, de acordo com Robles et al [5].

(2) Valor gasto na produção de novos materiais a partir de sua matéria prima, tendo por base o valor de $\mathrm{R} \$ 0,35 / \mathrm{KWh}$ praticado pela Copel (Companhia Paranaense de Energia).

Pela tabela 3 , vê-se que seriam necessários $\mathrm{R} \$$ $740.719,00$ para se produzir as 335,9 ton de material arrecadado. Evidentemente, esse valor se reduz significativamente com a introdução do material reciclado na fabricação de novos materiais. É o que mostra a Tabela 4, que apresenta o total gasto para os mesmos materiais, caso fossem produzidos a partir do material reciclado.

Tabela 4 -Valor gasto na produção de novos materiais a partir do material arrecadado e total economizado com a reciclagem.

\begin{tabular}{ccccc}
\hline Material & $\begin{array}{c}\text { Quanti } \\
\text { dade } \\
\text { (ton) }\end{array}$ & $\begin{array}{c}\text { Energia } \\
\text { necess. } \\
(\mathbf{M W h . t o} \\
\left.\mathbf{n}^{-\mathbf{1}}\right)^{(\mathbf{1})}\end{array}$ & $\begin{array}{c}\text { Total } \\
(\mathbf{R} \$)^{(\mathbf{2})}\end{array}$ & $\begin{array}{c}\text { Total } \\
\text { economiza } \\
\text { do c/ a } \\
\text { reciclagem } \\
(\mathbf{R} \mathbf{)})\end{array}$ \\
\hline Metal & 9,4 & 0,7 & $\begin{array}{c}2.310,0 \\
0\end{array}$ & $55.594,00$ \\
Papel e & 133,0 & 1,47 & $\begin{array}{c}68.425, \\
00\end{array}$ & $163.394,00$ \\
papelão & & & 54.670, & $184.532,00$ \\
Plástico & 101,4 & 1,54 & 00 & 107.625 \\
Vidro & 73,4 & 4,19 &, 00 & $16.458,00$ \\
Total & 335,9 & - & 233.030 & $419.978,00$ \\
\hline
\end{tabular}

(1) Energia gasta para fabricação de 1 tonelada do produto final a partir do material reciclado, de acordo com [5].

(2) Valor gasto na produção de novos materiais a partir de seu respectivo material reciclado, tendo por base o valor de $\mathrm{R} \$ 0,35 / \mathrm{KWh}$ praticado pela Copel (Companhia Paranaense de Energia).

Comparando-se as Tabelas 3 e 4 (total economizado com a reciclagem) vê-se, nesse caso, a grande economia que se obtém ao se utilizar material reciclado na fabricação de novos produtos. A economia obtida na fabricação de metal chega a $96 \%$; no caso do papel e papelão, $70,5 \% ; 78 \%$ para o plástico e $13,2 \%$ no caso do vidro. Esses percentuais representaram uma economia total de cerca de $\mathrm{R} \$ 420.000,00$ em apenas 1 ano do programa de coleta seletiva. Ou seja, R\$ 420.000,00 que seriam literalmente aterrados, caso não fosse implantado o programa.

\section{CONCLUSÕES}

Os benefícios da reciclagem de materiais se apresentam em vários aspectos: ambientais, sociais e econômicos, que devem ser levados em consideração a longo prazo, em contraposto aos recursos financeiros iniciais despendidos na implantação de um sistema de coleta seletiva.

Pode-se concluir que o objetivo do projeto no decorrer de seu primeiro ano foi alcançado, pois, além de toda a área urbana de Irati estar sendo atendida pelo programa de coleta seletiva, a associação dos catadores já alcançou sua autosustentabilidade.

Ainda assim, a taxa de material arrecadado alcançou, algumas vezes, rendimentos inferiores aos desejados, já que muitas vezes o material reciclável teve de ser vendido a sucateiros da região a um preço menor que o de mercado, por não alcançar peso suficiente de modo a viabilizar a venda direta às indústrias recicladoras dos 
grandes centros. Conclui-se, portanto, que além da verba mensal de três meses, é necessário um fundo de reserva para a associação manter a renda mensal dos associados no primeiro ano. Foi verificado também, que um maior volume de material coletado necessitaria a ampliação do barracão bem como na aquisição de um segundo caminhão.

Para garantir a autossustentabilidade e maior aproveitamento dos materiais, a cooperativa necessita melhorar sua gestão e passar a contribuir para um fundo específico para a aquisição de materiais recicláveis. Com um trabalho dessa natureza, sem haver rateio do fundo por um período de 12 meses, por exemplo, a cooperativa tende a ter um valor significativo, podendo concorrer com empresários locais na comercialização dos materiais.

Há necessidade ainda de prever novas campanhas de educação ambiental com distribuição de "folders" e cartilhas para atrair cada vez mais adeptos à coleta seletiva, envolvendo mais bairros da cidade em parceria com outras instituições que venham a se inserir no processo e incentivo da população já adepta com prêmios, como baldes personalizados. Os estudantes de $1^{\circ}$ e $2^{\circ}$ graus devem ser envolvidos diariamente com o tema, isso pode ser realizado de diversas formas, como a realização de teatros e atividades educativas, gincanas envolvendo as escolas com o tema da reciclagem e a implantação da coleta seletiva nas escolas da zona urbana e PEV (Postos de Entrega Voluntária) na zona rural.

\section{EVALUATION OF IMPLANTATION OF A SELECTIVE COLLECTING PROGRAM IN SMALL COUNTIES}

ABSTRACT: In general, the management of the municipal solid waste is being carried through a precarious way by the Brazilian municipal administrations. However, according to the IBGE, it's being verified a strong improvement trend in the final destination of the garbage collected in the country last years. The generation of wastes depends on some factors such as cultural level, consumption habits, income, climate, sex and age of the population and its reduction is related to a management program based on three aspects: reduction in the source, reusing and recycling. This present work focus on implantation of a selective collecting program in the urban area of Irati city (PR) through the Collectors Association. The proposal of implantation of the selective collecting was divided in two stages: logistics and environmental education, both already being fulfilled. In the twelve first months of the program, the results had shown a considerable increasing in the volume of material collected since the beginning of the program reaching $11.5 \%$ of the material generated in the city providing fixed job and income for 24 collectors who had been so far worked informally in the streets of the city. Based on amount collected in 12 months, it concluded that the saving can get $\mathrm{R} \$ 420.000,00$, if all recicled is utilized like raw material in the production of new products.

Keywords: Garbage; Irati (PR); Recycling; Selective collecting program; Municipal solid wastes.

\section{REFERÊNCIAS:}

1. AGENDA 21. Conferência das Nações Unidas sobre Meio Ambiente e Desenvolvimento. Rio de Janeiro, 1992. Disponível em: <http://www.ecolnews.com.br/agenda21/index.htm>. Acesso em: 25/12/07.

2. BROWN, D. T. The Legacy of the Landfill: Perspectives on the solid crisis. Plastics Waste Management: Disposal, Recycling, and Reuse. New York: Marcel Deker, 1993.

3. ROLIM, A. M. A Reciclagem de Resíduos Plásticos Pós-consumo em Oito Empresas do Rio Grande do Sul. 2000. 142f. Dissertação (Mestrado em Administração) - Universidade Federal do Rio Grande do Sul, Porto Alegre. 2000.

4. CALDERONI, S. Os bilhões perdidos no lixo. 2. Ed. São Paulo: Humanitas Publicações, 1998.

5. ROBLES Jr., A. J. et al. Mensuração econômica e financeira dos ganhos ambientais evitados da cidade de Belo Horizonte-MG. In: CONGRESSO BRASILEIRO DE CUSTOS, 10., 2003, Guarapari, Anais... Guarapari (ES), 2003.

6. CEMPRE - Compromisso empresarial para reciclagem. Mais um posto avançado do CEMPRE no mundo. Disponível em <http://www.cempre.org.br/imprensa.php?codeps= $8 \mathrm{fHx} 8 \mathrm{fHx} 8 \mathrm{fDQ}=>$. Acesso em: 07/12/07.

7. SOUZA, P. R. B. Parceria na Coleta Seletiva de Londrina sob a Ótica da Economia dos Custos de Transação: Um estudo de Caso. 2005. $234 \mathrm{f}$ Dissertação (Mestrado em Administração) - Universidade Estadual de Maringá, Maringá. 2005.

8. BUCKLAND, M. Information. In: Information and information systems. New York: Praeger, cap. 1: 3-13, 1995.

9. MAGERA, M.; ROBLES, D.; FIOCCO, D. Viabilidade Econômica da Reciclagem dos Resíduos Sólidos - VERDES. Disponível em $<$ http://reciclaveis.com.br.outsys.net/verdes/>. Acesso em 13/12/07.

10. HYMAN, H. H.; SHEATSLEY, P. B. Public Opinion Quartely, vol. 11, p. $412-423,1947$.

11. FERREIRA, D. A. A. A informação no projeto de coleta seletiva de papel nas unidades pertencentes à UFMG. 2003. 120f. Dissertação (Mestrado em Ciência da Informação) - Universidade Federal de Minas Gerais, Belo Horizonte. 2003.

12. ANGELIS NETO, G.; ANGELIS, B. L. D. Sanare: Revista Técnica da Sanepar, vol. 15 , n. 15 , p. $36-47,2001$. 